\title{
Treinamento nas micro e pequenas empresas e rotatividade de pessoal
}

\section{Micro and small enterprises training and employees turnover}

Djair Picchiai - Doutor em Administração de Empresas pela Escola de Administração de Empresas de São Paulo da Fundação Getúlio Vargas (EAESP). Professor pesquisador dos programas de Doutorado Acadêmico e de Mestrado Profissional em Administração da Faculdade Campo Limpo Paulista (FACCAMP). E-mail: djair.picchiai@fgv.br

Rodrigo Fernandes - Mestre em Administração pelo Centro Universitário Campo Limpo Paulista (UNIFACCAMP). Professor do Centro Estadual de Educação Tecnológica Paula Souza (CEETEPS). E-mail: fernandesoc@gmail.com

\begin{abstract}
Resumo
O objetivo deste artigo é compreender a percepção dos proprietários e funcionários em relação à aplicação de treinamentos nas Micro e Pequenas Empresas (MPEs) e a intenção de rotatividade de pessoal. As MPEs têm uma grande representatividade no contexto econômico e social no Brasil, e mudanças em seu comportamento organizacional podem refletir em seus resultados. Este estudo tem característica qualiquantitativa, exploratória com estudo de casos múltiplos. Para compreender o processo estudado, foram realizadas pesquisas com 31 empresas, em que 31 proprietários e 66 funcionários no município de Osvaldo Cruz (SP) participaram da amostra. Para a coleta de dados, foram utilizados questionários e formulários. Os resultados apresentaram relação entre o treinamento e a rotatividade. Este estudo contribui também para despertar a importância na elaboração e na implementação de políticas de aprendizagem para a capacitação das pessoas nas MPEs e sua influência no comportamento organizacional.
\end{abstract}

\section{Palavras-chave}

Treinamento. Rotatividade. Micro e Pequenas Empresas. Aprendizagem.

\begin{abstract}
The objective of this article is to understand the perception of owners and employees regarding training in Micro and Small Enterprises (MSEs) and employee turnover. MSEs have a great representation in the economic and social context in Brazil and changes in their organizational behavior can reflect on their results. This study has a qualitative-quantitative, exploratory character with multiple case studies. To understand the process, we conducted surveys with 31 companies, in which 31 owners and 66 employees in the municipality of Osvaldo Cruz (SP) participated in the sample. For the data collection, the authors used questionnaires and forms. The results showed a relationship between training and turnover. This study also address the importance in the elaboration and implementation of learning policies for the training of employees in MSEs and their influence on organizational behavior.
\end{abstract}

\section{Keywords}

Training. Turnover. Micro and Small Enterprises. Learning Process. 


\section{INTRODUÇÃO}

A prática de treinamento facilita a aprendizagem dos indivíduos e contribui para atingir resultados e objetivos das organizações, sendo um processo relacionado à área de gestão de pessoas (GP). Demo et al. (2011, p. 16) dizem que a "gestão de pessoas não deve ter papel tradicional de suporte, mas, sim, constituir competência essencial organizacional, uma vez que os recursos humanos $(\mathrm{RH})$ são responsáveis pela produção de conhecimento".

No entanto, muitas organizações não aplicam métodos de treinamento, ou não apresentam uma estrutura formalizada para o desenvolvimento dos funcionários. Tal fato pode implicar em falta de capacitação do pessoal e prejudicar a empresa na execução de suas ações estratégicas. De acordo com Malvezzi (2013, p. 06), "neste presente momento histórico, a gestão dos negócios e seu braço direito, a gestão das pessoas, são atividades necessárias e desafiadoras para os gestores, para a sociedade e para as ciências".

Carvalho e Mourão (2014) ressaltam que as organizações têm que perceber as constantes mudanças que vêm ocorrendo, principalmente no desenvolvimento dos empregados, avaliando fatores como a inovação e concorrência. Gonçalves e Mourão (2011) avaliam que é um investimento de extrema importância, relacionado ao contexto organizacional e, tendo um forte vínculo, com as estratégias das empresas.

Os dados do IPEA (2014) mostram que as MPEs merecem atenção especial pelo fato de atuarem em setores intensivos de trabalho. A rotatividade, no cenário brasileiro atual, mostra-se muito elevada neste mercado de trabalho, incorrendo em grande instabilidade na retenção de funcionários e no acúmulo de experiências capazes de promover maior ascensão profissional.

Robbins, Judge e Sobral (2010) destacam que índices de rotatividade altos causam falta de eficiência, principalmente pela saída de pessoas experientes e treinadas, e necessidade de contratação de substitutos para essas posições. É fato que todas as empresas, inevitavelmente, possuem certo índice de rotatividade, fator difícil de ser evitado. Dentro desse cenário, em um mercado cada vez mais competitivo, compreender a aplicação de treinamento no ambiente das MPEs e seus reflexos torna-se fundamental.

Sabe-se que o processo de qualificação dos funcionários pode gerar modificações nos índices de rotatividade e, ainda, tem se tornado objeto de estudo em muitas pesquisas. Os novos modelos de gestão buscam melhorar os resultados para as organizações e compreender os fatores que geram a rotatividade. 
Diante disso, este artigo tem como objetivo identificar a relação do treinamento com a rotatividade de pessoal no ambiente das MPEs.

\section{REFERENCIAL TEÓRICO}

\subsection{CONCEITOS E ESTUDOS SOBRE TREINAMENTO}

Diante de um conjunto amplo de definições e conceituações sobre treinamento, torna-se necessário identificar quais possibilitam melhor orientação neste estudo. Neste caso, um quadro explicativo de definições baseadas em autores renomados fortalece essa busca de orientação a fim de atingir os objetivos propostos. No Quadro 1, há exemplos de definições que contribuirão para o estudo.

Quadro 1 - Conceitos de treinamento

\begin{tabular}{|l|l|}
\hline \multicolumn{1}{|c|}{ Descrições } & \multicolumn{1}{|c|}{ Autores } \\
\hline $\begin{array}{l}\text { O treinamento pode incluir tudo, desde ensinar leitura básica até } \\
\text { cursos avançados de liderança. }\end{array}$ & $\begin{array}{l}\text { Robbins, Judge e } \\
\text { Sobral (2010, p. 539) }\end{array}$ \\
\hline $\begin{array}{l}\text { O treinamento é uma atividade materializada por diferentes } \\
\text { ritmos, apresentados por meio de visões distintas, implantadas } \\
\text { de acordo com vários propósitos, e reguladas pela dinâmica de } \\
\text { competição econômica. }\end{array}$ & $\begin{array}{l}\text { Malvezzi } \\
(2013, \text { p. 14) }\end{array}$ \\
\hline $\begin{array}{l}\text { Treinamento não é algo que se faça uma vez para novos } \\
\text { empregados: é usado continuamente nas organizações bem } \\
\text { administradas. Cada vez que você mostra a uma pessoa como } \\
\text { ela deve fazer o trabalho, você está treinando. Preferimos definir } \\
\text { treinamento como qualquer atividade que contribua para tornar } \\
\text { uma pessoa apta a exercer sua função ou atividade, para aumentar } \\
\text { a sua capacidade para exercer de forma eficiente novas funções } \\
\text { ou atividades. }\end{array}$ & \\
\hline $\begin{array}{l}\text { O treinamento é o uso de atividades de instrução sistemática e e } \\
\text { planejada para promover a aprendizagem. }\end{array}$ & \\
\hline $\begin{array}{l}\text { Treinamento é o conjunto de métodos usados para transmitir } \\
\text { aos funcionários novos e antigos as habilidades necessárias para } \\
\text { o desempenho do trabalho. }\end{array}$ & $\begin{array}{l}\text { Armstrong } \\
(2006, \text { p. 675) }\end{array}$ \\
\hline $\begin{array}{l}\text { O treinamento de pessoal é caracterizado pelo esforço } \\
\text { dispendido pelas organizações para propiciar oportunidades de } \\
\text { aprendizagem aos seus integrantes. }\end{array}$ & $\begin{array}{l}\text { Borges-Andrade } \\
\text { (2003, p. 140) }\end{array}$ \\
\hline $\begin{array}{l}\text { O treinamento é apenas uma das intervenções que afetam } \\
\text { desempenho no trabalho. É, portanto, somente uma das tentativas } \\
\text { formais de garantir a aquisição de novos conhecimentos, } \\
\text { habilidades e maior compreensão da tarefa, não afetando, } \\
\text { necessariamente, condições organizacionais (materiais e sociais) } \\
\text { relacionadas ao desempenho. }\end{array}$ & $\begin{array}{l}\text { Lacerda e Abbad } \\
(2003, \text { p. 79) }\end{array}$ \\
\hline
\end{tabular}

Fonte: Elaborado pelos autores, 2016. 
Gonzalez (2006) afirma que os temas treinamento e desenvolvimento são uns dos processos de recursos humanos mais discutidos nas últimas duas décadas. Isto vem ocorrendo pelo fato de se tratar de processos que atendem aos objetivos da empresa e aperfeiçoam as competências dos colaboradores.

Vários autores demonstram preocupação em relação aos investimentos realizados tanto no processo de treinamento quanto no treinamento como investimento (ROBBINS, 2004; LACOMBE, 2005; FERREIRA; FORTUNA; TACHIZAWA, 2006; LACERDA; ABBAD, 2003; GONÇALVES; MOURÃO, 2011; SILVA, 2006; ZERBINI; ABBAD, 2010; ROBBINS; JUDGE; SOBRAL, 2010; ZERBINI; ABBAD, 2005).

Para Robbins (2004), os funcionários passam por processos de treinamento para permanecer desenvolvendo suas competências. Segundo Lacombe (2005), o processo de treinamento deve ocorrer de forma contínua, uma vez que as empresas necessitam de algumas qualificações específicas. Para Ferreira, Fortuna e Tachizawa (2006), é necessário desenvolver novas habilidades ou aperfeiçoar as atuais, para repercutir no desempenho das tarefas, sendo importante encontrar a técnica adequada para aplicação.

De acordo com Lacerda e Abbad (2003), as organizações buscam avaliar seus investimentos na área de treinamento e do retorno proporcionado para a empresa. Assim, há o questionamento em relação às ações de treinamentos e sua eficácia no ambiente organizacional. Já Gonçalves e Mourão (2011) e Silva (2006) avaliam o treinamento como algo fortemente vinculado às estratégias da empresa, podendo influenciar e ser influenciado, devendo, desta forma, estar alinhado com seu objetivo e ambiente.

Zerbini e Abbad (2010) e Robbins, Judge e Sobral (2010) relatam a existência de investimentos em treinamentos por empresas ao redor do mundo, com desenvolvimento de ações formais na busca de transferência de conhecimento para o ambiente de trabalho. Para Lacerda e Abbad (2003), um dos questionamentos apresentados nas organizações é o retorno do investimento em treinamento e a eficácia de suas ações, sendo que, entre as indagações, encontrase a falta de confirmação dos resultados da aplicação de treinamento. Zerbini e Abbad (2005) citam a falta de processo na aplicação de treinamento, tais como levantamento de necessidade e avaliação dos resultados, que geram, muitas vezes, intervenções não apropriadas à realidade das organizações, mesmo com altos índices de aplicação de recursos financeiros. 
Conforme mencionado por Brown (1999), Webster, Walker e Brown (2005) e Dawe e Nguyen (2007), as pequenas empresas também passam por experiências com o processo de treinamento em seu ambiente. De acordo com Brown (1999), identifica-se que, embora as empresas de grande porte estejam mais disponíveis a oferecer treinamento em relação às pequenas empresas, o tamanho já não é um obstáculo em relação à aplicação do treinamento, visto que com as novas tecnologias, as pequenas empresas estão investindo mais em aplicação de treinamentos.

Webster, Walker e Brown (2005) destacam a importância de proprietários e funcionários nas pequenas empresas conhecerem melhor suas necessidades de treinamentos. Dawe e Nguyen (2007), em uma pesquisa realizada na Austrália, identificaram que as pequenas empresas representam metade dos empregos no país. No entanto, apenas um terço destas empresas oferecem programas de treinamento estruturado aos seus funcionários. A pesquisa apresenta que estas empresas aprendem mais por meio do fazer, no dia a dia do trabalho.

A aplicação de treinamento formal se justifica mediante as seguintes situações: necessidade de instruções formais, demanda pelo desenvolvimento de habilidades com maior rapidez, insuficiência na iniciativa do profissional para realizar tarefas especializadas ou complexas (ARMSTRONG, 2006). Embora haja vários meios para o desenvolvimento das potencialidades humanas, tais como rotinas, experiências e educação, o treinamento se destaca por atender as necessidades de adaptação profissional e por ser a ferramenta mais comum, visto que apresenta uma enorme diversidade de aplicações, tal como transformar a potencialidade humana em habilidade (MALVEZZI, 2013).

Segundo Nonaka e Takeuchi (2008), o treinamento no trabalho utilizase do princípio relacionado à aprendizagem por meio do conhecimento tácito, demonstrando que a transferência de informações sem a oportunidade de experiência pode gerar dificuldades de compreensão por parte do outro indivíduo. Em uma última análise acerca da compreensão do assunto, o comportamento do líder tem forte influência no impacto do treinamento e do desenvolvimento de seus subordinados, levando à reflexão em relação ao preparo dos líderes, principalmente no que se refere ao relacionamento interpessoal (SILVA; MOURÃO, 2015). 


\subsection{TIPOS DE TREINAMENTO E SEUS MÉTODOS E TÉCNICAS}

Robbins (2004) cita alguns métodos de treinamentos formais e informais utilizados no ambiente empresarial, afirmando que treinar relaciona-se a ministrar treinamento formal com planejamento prévio e processo estruturado. Porém, observa-se que as organizações utilizam cada vez mais treinamento no formato informal, sendo que este modelo se relaciona ao processo de colaboração entre os funcionários da organização, com a transferência de conhecimento entre eles.

Neste contexto, Lacombe (2005) apresenta os tipos de treinamento quanto às suas formas de execução, podendo ocorrer a distância, formal, interno, externo e no trabalho.

Alguns empregadores têm centros internos de desenvolvimento que normalmente combinam aulas presenciais (palestras e seminários, por exemplo) e outras técnicas, como centros de avaliação, exercícios de caixa de entrada e representação de papéis para auxiliar o desenvolvimento de funcionários e gerentes (DESSLER, 2003, p. 155).

Para Saccol et al. (2010), o e-learning envolve o ensino de alunos que podem estar fisicamente e geograficamente distantes, sem a necessidade de frequentar o mesmo espaço físico para o seu processo de desenvolvimento, como sala de aula e outros locais tradicionais. Por sua vez, o programa de integração de novos colaboradores tem por objetivo a informação referente a políticas, estratégias, produtos, benefícios, normas, horários, prática, entre outros (LACOMBE, 2005).

\subsection{CRENÇAS SOBRE O SISTEMA DE TREINAMENTO}

Entre as análises para o desenvolvimento da pesquisa, encontra-se o estudo das crenças sobre o sistema de treinamento. Para compreender e interpretar este fenômeno, foi necessária uma avaliação das definições e a análise de pesquisas relacionadas.

Algumas crenças influenciam a atitude das pessoas em direção a um dado comportamento. Isso ocorre porque a pessoa acredita que a exibição daquele comportamento levará a certas consequências, que aquela pessoa avalia como importantes (Teoria da Expectância) (LOPES; MOURÃO, 2010, p. 205).

Lopes e Mourão (2010) destacam que no ambiente das empresas, quando novos funcionários integram a equipe de trabalho, os funcionários atuais passam 
a relatar suas crenças em relação ao sistema de Treinamento, Desenvolvimento e Educação (TD\&E) aplicado no ambiente da empresa.

Crenças podem ser compreendidas como elementos de representação mental, abstratos, oriundos de experiências individuais e coletivas que, uma vez alcançando o formato e o suporte físico necessário à sua objetivação, oferecem-se à crítica (LOPES; MOURÃO, 2010, p. 199).

Em pesquisa realizada com sete empresas do setor privado, as autoras detectaram que "a experiência de trabalho, o salário, a idade e o tempo de trabalho têm influência nas crenças relativas aos Sistemas de Treinamento" (LOPES; MOURÃO, 2010, p. 205).

Freitas e Borges-Andrade (2004) são os responsáveis pelo desenvolvimento da Escala de Crenças sobre o Sistema Treinamento (ECST). Os autores relatam que "segundo a literatura, crenças e atitudes, até mesmo as mais gerais, influenciam a transferência de treinamento" (FREITAS; BORGES-ANDRADE, 2004, p. 480).

\subsection{ROTATIVIDADE DE PESSOAL NO AMBIENTE ORGANIZACIONAL}

Para Robbins (2005, p. 22) e Siqueira et al. (2014), a rotatividade "é a permanente saída e entrada de pessoal da organização, de forma voluntária ou involuntária". Sabe-se que alto índice de rotatividade pode significar aumento nos custos dos processos de recrutamento, seleção e treinamento, causando ruptura no desenvolvimento da empresa, visto que isso pode reduzir a eficiência da organização. Por outro lado, novas pessoas estão sendo incorporadas para o desenvolvimento da organização. Zardin Patias et al. (2015) observam que "o custo total da rotatividade de pessoal é composto pelo somatório dos valores dos custos de desligamento, reposição e treinamento".

Com os resultados apresentados em pesquisa, Agapito et al. (2015) demonstram que para reduzir a intenção dos profissionais em abandonar as organizações, deve-se desenvolver um ambiente de trabalho estimulante e agradável. Para Ferreira e Siqueira (2005), algo que preocupa os gestores de pessoas é a busca por maior competitividade, assim uma atenção especial é dada com a manutenção dos talentos e a redução da rotatividade. Silva, Cappellozza e Costa (2014) afirmam que a rotatividade pode gerar perdas estratégicas e operacionais para as organizações.

Conforme apresentado por Gonzaga e Cayres Pinto (2014), a baixa produtividade aferida no Brasil tem como uma das possíveis causas a alta 
rotatividade de pessoal no trabalho, devido ao baixo investimento no capital humano. Sobral e Peci (2008) e Cardoso, Freitas Cardoso e Santos (2013) relatam que para aumentar a produtividade e reduzir a rotatividade de pessoal, é necessário entender o comportamento dos trabalhadores, como suas atitudes, percepções, aprendizagem e comportamento individual. Segundo Pequeno (2012, p. 35), "a rotatividade alta também pode indicar falhas no recrutamento e na seleção, o que deve levar o RH a rever seus próprios processos". A diminuição da rotatividade de pessoal também é citada por Freire (2014), como um impacto nos resultados de avaliação de treinamentos e nos resultados organizacionais.

\subsubsection{Relacionamento do treinamento com a intenção de rotatividade}

Nos estudos apresentados por Pequeno (2012) para avaliar as necessidades de treinamento, pôde-se utilizar algumas ferramentas para esta pesquisa, como: mapeamento de competências, questionários, entrevistas; avaliação de desempenho; e indicadores, tal como o alto índice de ausência no trabalho ou a rotatividade.

Para melhor compreender o efeito do treinamento em relação ao ambiente empresarial, Freire (2014) demonstra que quanto maior o desempenho do participante no treinamento, maiores serão os impactos no ambiente organizacional e em seus resultados, como a diminuição da rotatividade de pessoal.

Os resultados apresentados por Ferreira e Almeida (2015), em pesquisa realizada para avaliar a relação entre a rotatividade de funcionários e o desempenho organizacional no setor de comércio, constataram que a empresa em questão apresentava dificuldades em manter funcionários qualificados. Da mesma forma, a pesquisa realizada por Freitas et al. (2015) observou existir uma relação negativa entre oportunidade de aprendizagem e intenção de rotatividade.

Entre as abordagens de retenção de funcionários, Dessler (2014) apresenta um programa de retenção abrangente em suas investigações, em que um dos fatores identificados relaciona-se ao crescimento profissional. O autor relata que funcionários com baixo incentivo de desenvolvimento profissional e sem perspectiva de carreira tendem a sair das empresas. Por outro lado, quando há incentivos no desenvolvimento de carreira e de treinamentos, estes atuam em favor da permanência na empresa. 


\section{MÉTODO}

Esta pesquisa está delimitada ao levantamento de dados em MPEs do segmento de serviços e comércio no município de Osvaldo Cruz (SP), tendo como questão central do estudo a avaliação do relacionamento da aplicação de treinamentos com a intenção de rotatividade de pessoal. "O método é o conjunto das atividades sistemáticas e racionais que, com maior segurança e economia, permite alcançar o objetivo - conhecimentos válidos e verdadeiros" (MARCONI; LAKATOS, 2003, p. 83).

A presente pesquisa tem características qualitativas e quantitativas, associadas à técnica de método misto. A pesquisa que melhor se adapta ao presente estudo relaciona-se à pesquisa exploratória, por meio de levantamento bibliográfico e de campo. Este modelo de pesquisa normalmente envolve estudos de caso, além de outras técnicas, e assim para o presente estudo, utilizou-se a estratégia de pesquisa de estudo de casos múltiplos, já que segundo Yin (2005), casos múltiplos são relacionados a levantamentos múltiplos.

Segundo Marconi e Lakatos (2003, p.163), “a amostra é uma parcela conveniente selecionada do universo (população); é um subconjunto do universo". Neste artigo, optou-se por aplicar a pesquisa no município de Osvaldo Cruz (SP). Sendo assim, a amostra será não probabilista de forma intencional. Atualmente o município conta com 3.056 empresas registradas, sendo a maioria MPEs.

Durante o processo de levantamento de dados, visitou-se nos meses de setembro, outubro, novembro e dezembro de 2017, um número razoável de empresas, sendo que 31 aceitaram participar da pesquisa, compondo a amostra estudada. Em relação à participação dos proprietários e funcionários, a pesquisa obteve uma amostra formada por 31 proprietários/responsáveis e 66 funcionários. Das 31 empresas participantes, 16 são do segmento do comércio e 15 prestadoras de serviços. Em relação ao enquadramento, participaram 22 Micro Empresas (MEs) e nove Empresas de Pequeno Porte (EPP).

Os instrumentos utilizados no desenvolvimento da pesquisa foram questionários apresentados aos participantes no momento da coleta de dados. O questionário aplicado com os sócios-proprietários foi desenvolvido conforme pesquisas realizadas e apresentadas no referencial teórico e escalas aplicadas em estudos relacionados aos temas. Entre as escalas utilizadas estão a Escala 
de Crenças sobre o Sistema Treinamento (ECST), Escala de Intenção de Rotatividade (EIR), e também um instrumento desenvolvido para pesquisa, a Escala de Relacionamento de Treinamento e Rotatividade (ERTR).

A ECST relaciona-se a uma escala aplicada por Freitas e Borges-Andrade (2004) em estudo para compreender as crenças nos sistemas de treinamento. Essa escala busca compreender três fatores: a) crenças sobre as contribuições do treinamento para o indivíduo e para a organização; b) crenças sobre o processo de levantamento de necessidades de treinamento e c) crenças sobre resultados e o processo de treinamento.

O instrumento segue uma escala do tipo Likert de 10 pontos, sendo 01 para "não acredito" e 10 para "acredito totalmente". Conforme Abbad et al. (2009, p. 287), "valores médios entre 1 e 4 indicariam uma descrença no sistema de treinamento, entre 4,1 e 7 indicariam uma crença moderada e entre 7,1 e 10 uma percepção positiva acerca desse sistema".

Em uma pesquisa realizada por Freitas e Borges-Andrade (2004), os coeficientes de confiabilidade alfa de Cronbach $^{1}$ apresentados foram de 0,94, 0,84 e 0,82 . No presente estudo, os resultados encontrados na amostra de funcionários seguiram índices muito próximos aos apresentados pelos autores citados acima, com 0,96, 0,85 e 0,91, indicando que os questionários utilizados apresentaram boa ou excelente consistência.

Segundo Siqueira et al. (2014, p. 212), “a EIR é uma medida que pretende avaliar o grau em que um indivíduo elabora planos sobre sua saída da empresa em que trabalha". A escala é formada por três frases relacionadas à intenção de rotatividade dos funcionários em relação à empresa em que trabalham, sendo avaliado se ele pensa, planeja e tem vontade de deixar de trabalhar na empresa. Com os dados coletados na pesquisa, o coeficiente de confiabilidade alfa de Cronbach apresentado foi 0,94, indicando ótima consistência.

A ERTR é uma escala tipo Likert que passou por uma validação para sua aplicação, onde na primeira etapa selecionou-se um conjunto de proposições relacionadas aos temas "treinamento e rotatividade". Conforme pesquisas apresentadas no referencial teórico, a escala é formada por cinco proposições, que foram testadas por especialistas e também foi realizada uma aplicação de um teste com 23 participantes, além de validação no software Statistical Package for

\footnotetext{
O coeficiente alfa de Cronbach foi apresentado por Lee J. Cronbach, em 1951, como uma forma de estimar a confiabilidade de um questionário aplicado em uma pesquisa (CRONBACH, MEEHL, 1955).
} 
the Social Sciences (SPSS), versão 17.0, com um índice de alfa de Cronbach de 0,83 com os funcionários e 0,73 com os proprietários.

$\mathrm{Na}$ primeira etapa da coleta de dados com os sócios-proprietários, o entrevistador controlou as características do porte da empresa, assim, tornou-se necessário a realização de uma investigação inicial para identificar o enquadramento da empresa, sendo realizada no ato da visita. Para maior aceitação da participação no processo, optou-se em manter sigilo do nome das empresas participantes e dos entrevistados.

Na segunda fase da coleta de dados foram aplicados questionários com os funcionários em cinco etapas, sendo identificação do entrevistado, aplicação de programas de treinamento, avaliação da percepção de rotatividade e treinamento, intenção de rotatividade e crenças no sistema de treinamento. Também, seguiramse os métodos de aplicação apresentados na primeira etapa.

\section{RESULTADOS}

$\mathrm{Na}$ análise do perfil demográfico e atividades profissionais dos 31 sóciosproprietários e/ou gerentes respondentes, a pesquisa revelou que 81\% dos participantes são representados pelos sócios-proprietários e apenas 19\% por gerentes responsáveis. Os resultados apontam que 45\% dos entrevistados estão a mais de dez anos à frente destas empresas e 28\% entre seis e dez anos. Quanto ao gênero dos participantes da pesquisa, pode-se identificar uma diferença relevante, com $77 \%$ dos entrevistados do sexo masculino e apenas $23 \%$ do sexo feminino.

Em relação à idade dos indivíduos que exercem a função de sóciosproprietários e/ou gerentes nas MPEs pesquisadas, 75\% da amostra é formada por profissionais acima de 30 anos de idade. Entre as análises realizadas, 81\% da amostra é composta por profissionais com ensino superior completo ou pósgraduação completa.

A amostra constituída pelos funcionários está formada por 66 indivíduos, dos quais 53\% são do gênero masculino e 47\% feminino, apresentando uma diferença significativa em relação aos sócios-proprietários e/ou gerentes, conforme apresentado na seção anterior. Entre os participantes, $71 \%$ são funcionários de ME enquanto 29\% estão em empresas classificadas como EPP. Predominantemente, 91\% dos funcionários exercem seus cargos em funções operacionais. 
Entre as 31 MPEs que participaram da pesquisa, foram identificadas 16 empresas pertencentes ao comércio (52\% da amostra), e 15 do segmento de serviços (48\% da amostra). Das empresas representantes do comércio, a distribuição é de (4) Comércio de Roupas, Calçados e Acessórios; (2) Farmácias; (2) Comércio de Móveis; (2) Loja de Produtos de Informática; (1) Oficina Mecânica; (1) Pet Shop; (1) Material de Construção; (1) Ótica; (1) Lanchonete e (1) Comunicação Visual. Em relação às empresas do segmento de serviços, a distribuição é de (3) Escritórios de Contabilidade; (1) Restauração Automotiva; (1) Desenvolvimento de Software; (1) Rádio; (1) Educação de Trânsito; (1) Imobiliária; (1) Desenvolvimento de Web; (1) Agência de Comunicação; (1) Corretora de Seguros; (1) Laboratório de Análise Clínica; (1) Clínica de Fisioterapia; (1) Academia e (1) Serviços de Internet.

As empresas, em sua maioria, têm um número entre dois e cinco funcionários (52\%), o segundo maior índice de funcionários está entre seis e nove $(22 \%)$ e empresas com apenas um funcionário, ou de dez a 19 representam o restante da amostra (26\%). A maioria das MPEs pesquisadas apresentadas possui mais de dez anos de atuação no mercado (52\%), já empresas que atuam entre seis a dez anos seguem em segundo lugar (29\%), enquanto empresas entre três e cinco anos de atuação no mercado representam o restante da amostra (19\%).

Em relação à classificação fiscal das empresas, há uma proporção maior de $\mathrm{ME}(71 \%)$ em relação às EPP (29\%). As ME representam um índice muito mais elevado em comparação às EPP no âmbito nacional. Para os resultados relacionados aos tipos de empresas, foi identificado um cenário com 68\% de empresas tradicionais e $32 \%$ de empresas familiares.

Em relação aos processos de treinamentos aplicados, os resultados foram avaliados quanto à frequência de aplicação dos programas de treinamentos; tipos de treinamentos aplicados aos funcionários; atividades realizadas no processo de treinamentos; orçamento para investimento em treinamento; instalações físicas necessárias para o treinamento; treinamento externo pago pela empresa; formação de instrutores (interno); práticas de recursos humanos; métodos e técnicas de treinamentos aplicados; interesse dos funcionários em participar dos programas de treinamento; consciência dos funcionários em relação aos programas de treinamento disponíveis; e frequência de absenteísmo na empresa.

Convém observar que em uma análise mais detalhada da aplicação dos tipos de treinamentos, foram encontrados os seguintes resultados: entre os 
maiores índices de aplicação, a categoria com maior destaque é o treinamento no trabalho, citado por 100\% das empresas da amostra; seguido do treinamento formal externo, mencionado por 21 empresas, e o treinamento de integração, citado por 14 empresas. Já o treinamento formal interno foi a categoria que apresentou o menor índice de aplicação entre as empresas.

Apesar de as empresas afirmarem que aplicam algum tipo de treinamento em seu ambiente de trabalho, conforme apresentado por Lacombe (2005), a determinação da quantidade de aplicação é algo relevante para o presente estudo. Neste contexto, a aplicação de treinamento aponta para resultados bem distintos no ambiente das MPEs da amostra. Neste caso, é evidente a preferência das empresas pelo treinamento no trabalho e sua intensidade de aplicação, onde 17 empresas afirmaram que aplicam este modelo semanalmente e 11 mensalmente. O modelo que mais se aproxima deste resultado é o treinamento formal externo, porém, seu maior índice de aplicação ocorre semestralmente. $\mathrm{O}$ treinamento formal interno apresenta resultados discretos em comparação aos modelos anteriores. Nesta análise, não foi avaliada a frequência de aplicação do treinamento de integração pelo fato de ser aplicado conforme a necessidade de entrada de novos funcionários.

O processo de levantamento de necessidades foi citado por 16 empresas, já o processo de planejamento e organização foi identificado 14 vezes, enquanto 16 empresas afirmaram que aplicam o treinamento para a avaliação dos resultados. Das 31 empresas pesquisadas, apenas quatro afirmaram que não aplicam nenhum processo, sendo que as perguntas apresentavam opções de assinalar todas as alternativas de respostas que se aplicam à realidade da empresa.

A falta de aplicação desses processos faz com que as empresas desenvolvam seus programas de treinamento dentro de uma informalidade, podendo gerar impactos em seus resultados. Por outro lado, não se pode deixar de observar que a maioria das empresas participantes da amostra aplicam atividades relacionadas a esses processos, algo que não é tão comum no ambiente das MPEs.

Outro fato a se destacar é a forma pela qual a gestão desses processos é realizada. Durante a aplicação da pesquisa, conforme relatado na seção Métodos, todos os questionários foram aplicados diretamente pelo pesquisador em contato com os sócios-proprietários e/ou gerentes. Não foram apresentados documentos que comprovassem a formalidade dos processos internos das empresas, o que inclui os treinamentos, realizados apenas por observações e análises, sendo que em muitos casos não há registros formalizados. 
Com a análise realizada para compreender se as empresas dispõem de orçamento para investimento em treinamento, ficou claro que, dentro da amostra estudada, não é uma prática constantemente aplicada, uma vez que praticamente $68 \%$ das empresas não têm um orçamento específico para a aplicação do treinamento. Entre os relatos dos entrevistados, muitos indicaram que aplicam os investimentos conforme necessidade momentânea.

Os métodos e técnicas de treinamentos encontrados no ambiente das empresas pesquisadas estão divididos, tendo destaque para a discussão em grupo, palestras e orientação da chefia. Outros métodos e técnicas também foram encontrados na aplicação do treinamento dentro da amostra pesquisada.

Um dos métodos pouco aproveitados no ambiente das MPEs pesquisadas é o Ensino a Distância. Apenas sete empresas aplicam esta metodologia. Além disso, algo que também chamou a atenção na pesquisa refere-se ao método de rotação de cargo, aplicado por apenas duas empresas da amostra.

Também foi possível identificar que em 23 empresas da amostra, os funcionários demonstram algum tipo de interesse em participar dos programas de treinamentos oferecidos, enquanto em 16 empresas os funcionários afirmam estar conscientes dos programas de treinamento oferecidos.

Outro fator avaliado foi uma análise com os funcionários em relação à oferta de treinamento por parte das empresas, sua participação nos treinamentos ofertados e sua experiência com treinamento em outras empresas. Os resultados apresentados demonstram que os funcionários confirmam a presença de oportunidades de treinamento no ambiente das MPEs da amostra, além de afirmarem um alto índice de participação nestes processos. Quando questionados em relação à experiência em treinamento em outras empresas, apenas 10\% nunca tiveram oportunidades e $23 \%$ afirmaram que raramente passaram pelo processo de treinamento.

Os resultados demonstram que os funcionários têm um alto índice de participação nos treinamentos, além de experiências em outras empresas, o que indica que o público pesquisado tem participação ativa neste processo, podendo contribuir com as análises propostas na pesquisa.

Uma vez que a análise da ECST tem extrema importância para o estudo, pois apresenta as crenças dos entrevistados sobre o sistema de treinamento aplicado nas MPEs, em análise realizada com os funcionários das empresas, constatou-se uma percepção positiva em relação ao sistema com uma média de 7,9. Além disso, em relação aos fatores separados, foi possível identificar uma percepção positiva, conforme resultados apresentados na Tabela 1. 
Tabela 1 - Resultados das análises da ECST apresentados pelos funcionários

\begin{tabular}{l|c|c|c|c}
\hline & Min & Max & M & DP \\
\hline $\begin{array}{l}\text { Crenças sobre as contribuições do treinamento para o } \\
\text { indivíduo e para organização }\end{array}$ & 2,1 & 10 & 8,2 & 1,9 \\
\hline $\begin{array}{l}\text { Crenças sobre o processo de levantamento de } \\
\text { necessidades de treinamento }\end{array}$ & 1,5 & 10 & 7,3 & 2,2 \\
\hline Crenças sobre resultados e o processo de treinamento & 2,4 & 10 & 8,1 & 1,8 \\
\hline Crenças sobre o Sistema Treinamento (Escala completa) & 2,0 & 10 & 7,9 & 2,0 \\
\hline
\end{tabular}

Fonte: Elaborado pelos autores, com base na pesquisa realizada (2016).

Legenda: Min: mínimo, Max: máximo, M: média, DP: Desvio Padrão.

Ao observar os resultados apresentados da ERTR, nota-se um grau de concordância entre os funcionários pesquisados. Nas quatro afirmativas relacionadas diretamente à rotatividade de pessoal, em que se buscou uma compreensão entre o relacionamento com o treinamento, identifica-se um grau de concordância nas respostas. A Tabela 2 apresenta os resultados em percentuais conforme coleta de dados da pesquisa.

Tabela 2 - Análise das respostas dos funcionários sobre relação de treinamento e rotatividade

\begin{tabular}{|c|c|c|c|c|c|c|c|c|}
\hline AFIRMATIVAS & DT & $\mathrm{D}$ & DP & TD & $\mathrm{CP}$ & $\mathrm{C}$ & $\mathrm{CT}$ & $\mathrm{TC}$ \\
\hline $\begin{array}{l}\text { 1. A contribuição do treinamento } \\
\text { minimiza sua intenção de sair da } \\
\text { empresa }\end{array}$ & 16,7 & 13,6 & & 30,3 & 25,8 & 37,9 & 6,0 & 69,7 \\
\hline $\begin{array}{l}\text { 2. As contribuições do } \\
\text { treinamento para equipe reduzem } \\
\text { a intenção de rotatividade dos } \\
\text { funcionários }\end{array}$ & 10,6 & 9,1 & 6,1 & 25,8 & 24,2 & 36,4 & 13,6 & 74,2 \\
\hline $\begin{array}{l}3 . \text { As contribuições do } \\
\text { treinamento para empresa } \\
\text { reduzem a intenção do superior } \\
\text { em não substituir/demitir o } \\
\text { funcionário }\end{array}$ & 3,0 & 15,2 & 1,5 & 19,7 & 21,2 & 45,5 & 13,6 & 80,3 \\
\hline $\begin{array}{l}\text { 4. A falta de treinamento } \\
\text { incentiva você buscar novas } \\
\text { alternativas de trabalho }\end{array}$ & 9,1 & 31,8 & 9,1 & 50,0 & 16,6 & 25,8 & 7,6 & 50,0 \\
\hline $\begin{array}{l}\text { 5. A contribuição do treinamento } \\
\text { reduz o absenteísmo (faltas e } \\
\text { atrasos) }\end{array}$ & 19,7 & 16,7 & 10,5 & 46,9 & 19,7 & 25,8 & 7,6 & 53,1 \\
\hline
\end{tabular}

Fonte: Elaborado pelos autores, com base na pesquisa realizada (2016).

Legenda: DT: discordo totalmente; D: discordo; DP: discordo um pouco; TD: total de discordância; CP: concordo um pouco; C: concordo; CT: concordo totalmente; TC: total de concordância. 
Observa-se na primeira afirmativa que $69,7 \%$ dos entrevistados concordam com a relação entre a aplicação de treinamentos e a intenção de sair da empresa; ou seja, pode-se interpretar que a contribuição do treinamento minimiza a intenção do funcionário em sair da empresa. Quando questionados, na segunda afirmativa, se as contribuições do treinamento para equipe reduzem a intenção de rotatividade dos funcionários, o índice de concordância se eleva para 74,2\%, seguido de $80,3 \%$, quando questionado se as contribuições do treinamento para empresa reduzem a intenção do superior em não substituir/demitir o funcionário. Os funcionários das MPEs da amostra estudada valorizam o treinamento em seu ambiente de trabalho.

A Tabela 2 ainda mostra que, para 50\% da amostra, a falta de treinamento incentiva os funcionários a buscarem novas oportunidades de trabalho. Outro fator abordado pela escala relaciona-se ao absenteísmo, que também é influenciado pelos treinamentos. Mais da metade dos respondentes $(53,1 \%)$ concordam com as contribuições dos treinamentos para diminuir faltas e atrasos.

Ainda nesse contexto, os sócios-proprietários e/ou gerentes também participaram das respostas relacionadas à ERTR, sendo que as afirmativas 1, 3 e 4 foram adaptadas em comparação à escala aplicada aos funcionários. O objetivo, no entanto, foi o mesmo; ou seja, relacionar a visão de cada cargo exercido na empresa.

Observa-se nas respostas apresentadas que o grau de concordância em relação ao impacto do treinamento na rotatividade segue a mesma linha, porém, há alguns fatores que apresentam resultados diferentes. A Tabela 3 segue mesma metodologia aplicada na Tabela 2, proporcionando uma comparação entre as opiniões desses dois públicos pesquisados.

Tabela 3 - Análise das repostas dos proprietários sobre relação de treinamento e rotatividade

\begin{tabular}{|c|c|c|c|c|c|c|c|c|}
\hline \multirow[b]{2}{*}{ AFIRMATIVAS } & \multicolumn{8}{|c|}{$\begin{array}{l}\text { FREQUÊNCIA DAS RESPOSTAS EM } \\
\text { PERCENTUAIS }\end{array}$} \\
\hline & DT & $\mathrm{D}$ & DP & TD & CP & C & CT & TC \\
\hline $\begin{array}{l}\text { 1. A contribuição do } \\
\text { treinamento minimiza a } \\
\text { intenção do funcionário de } \\
\text { sair da empresa }\end{array}$ & 9,7 & 16,1 & 9,7 & 35,5 & 29,0 & 25,8 & 9,7 & 64,5 \\
\hline
\end{tabular}




\begin{tabular}{|c|c|c|c|c|c|c|c|c|}
\hline $\begin{array}{l}\text { 2. As contribuições do } \\
\text { treinamento para equipe } \\
\text { reduzem a intenção } \\
\text { de rotatividade dos } \\
\text { funcionários }\end{array}$ & 6,5 & 25,8 & 6,5 & 38,7 & 16,1 & 38,7 & 6,5 & 61,3 \\
\hline $\begin{array}{l}\text { 3. As contribuições do } \\
\text { treinamento para empresa } \\
\text { reduzem sua intenção em } \\
\text { não substituir/demitir o } \\
\text { funcionário }\end{array}$ & & 6,5 & & 6,5 & 32,3 & 48,4 & 12,9 & 93,5 \\
\hline $\begin{array}{l}\text { 4. A falta de treinamento } \\
\text { incentiva o funcionário a } \\
\text { buscar novas alternativas de } \\
\text { trabalho }\end{array}$ & 9,7 & 12,9 & 6,5 & 29,0 & 32,3 & 22,6 & 16,1 & 71,0 \\
\hline $\begin{array}{lrr}\text { 5. A contribuição } & \text { do } \\
\text { treinamento } & \text { reduz } & \text { o } \\
\text { absenteísmo } & \text { (faltas } & \mathrm{e} \\
\text { atrasos) } & & \\
\end{array}$ & 6,5 & 16,1 & 6,5 & 29,0 & 19,4 & 35,5 & 16,1 & 71,0 \\
\hline
\end{tabular}

Fonte: Elaborado pelos autores, com base na pesquisa realizada (2016). Legenda: DT: discordo totalmente; D: discordo; DP: discordo um pouco; TD: total de discordância; CP: concordo um pouco; C: concordo; CT: concordo totalmente; TC: total de concordância.

Quando questionados se a contribuição do treinamento minimiza a intenção do funcionário de sair da empresa, os sócios-proprietários e/ou gerentes apresentaram uma concordância de $64,5 \%$, podendo reafirmar que há um impacto na relação das contribuições no treinamento com a rotatividade de pessoal. Seguindo esta análise, eles também concordaram com os funcionários que as contribuições do treinamento para equipe reduzem a intenção de rotatividade dos funcionários, com $61,3 \%$ de concordância.

Além disso, 93,5\% dos sócios-proprietários e gerentes da amostra estudada concordam que o treinamento reduz a intenção de substituir/demitir um funcionário, o que pode levar a compreender que eles veem o treinamento como um dos fatores que geram impacto na rotatividade de pessoal, com uma ênfase ainda maior do que os funcionários.

Outro fator relevante nesta comparação é que $71 \%$ dos sóciosproprietários e/ou gerentes acreditam que a falta de treinamento incentiva o funcionário a buscar novas alternativas de trabalho, índice este também com uma maior representatividade em comparação aos funcionários. Do mesmo modo, pode-se entender também que o treinamento reduz o absenteísmo. 
Neste mesmo contexto, na Tabela 4 é possível observar que há uma diferença mais expressiva entre as opiniões dos funcionários, sócios-proprietários e/ou gerentes em relação às afirmativas $2,3,4$ e 5 .

Tabela 4 - Diferenças entre as respostas de sócios/proprietários e/ou gerentes responsáveis e funcionários

\begin{tabular}{l|c|c|c|c}
\hline & \multicolumn{2}{|c|}{ PROPRIETÁRIOS } & \multicolumn{2}{c}{ FUNCIONÁRIOS } \\
\hline AFIRMATIVAS & TD & TC & TD & TC \\
\hline AFIRMATIVA 1 & 35,5 & 64,5 & 30,3 & 69,7 \\
\hline AFIRMATIVA 2 & 38,7 & 61,3 & 25,8 & 74,2 \\
\hline AFIRMATIVA 3 & 6,5 & 93,5 & 19,7 & 80,3 \\
\hline AFIRMATIVA 4 & 29,0 & 71,0 & 50,0 & 50,0 \\
\hline AFIRMATIVA 5 & 29,0 & 71,0 & 46,9 & 53,1 \\
\hline
\end{tabular}

Fonte: Elaborado pelo autor, com base na pesquisa realizada (2016).

Legenda: TD: total de discordância e TC: total de concordância.

Ressalta-se que há uma média de aproximadamente 30\% (afirmativa 5 desconsiderada) retratada na Tabela 2 e Tabela 3, em que os entrevistados apontam um grau de discordância em relação às contribuições do treinamento com a rotatividade de pessoal.

Todas as orientações de aplicação determinadas por Siqueira et al. (2014) para aplicação da escala EIR foram seguidas nesta pesquisa, sendo que os funcionários das MPEs responderam de forma individual e com liberdade para expressar seus sentimentos em relação a sua intenção de rotatividade, utilizando o tempo necessário para refletir sobre o assunto. Em nenhum momento os funcionários das empresas foram coagidos, e todas as instruções para interpretação da escala foram explicadas. Quando necessário, um dos autores se fez presente para quaisquer esclarecimentos adicionais.

Vale destacar que os resultados apresentados por Siqueira et al. (2014) estão divididos da seguinte forma: alto para um escore entre 4 e 5; médio para um escore entre 3 e 3,9, e baixo para escore entre 1 e 2,9. A Tabela 5 apresenta as frequências em percentuais coletados na amostra, em que 47 participantes apresentaram um escore baixo (71\% da amostra), 15 apresentaram um escore médio $(23 \%)$ e apenas quatro apresentaram um escore alto $(6 \%)$. O resultado geral da amostra apresentou um escore baixo, com um índice de 2,04. 
Tabela 5 - Frequência em percentuais de respostas para EIR

\begin{tabular}{l|c|c|c|c|c}
\hline \multicolumn{7}{c}{ FREQUÊNCIA DAS RESPOSTAS EM PERCENTUAIS \% } \\
\hline \multicolumn{1}{c|}{ AFIRMATIVAS } & $\mathrm{N}$ & $\mathrm{R}$ & $\mathrm{AV}$ & $\mathrm{F}$ & $\mathrm{S}$ \\
\hline 1. Penso em sair da empresa onde trabalho & 40,9 & 25,8 & 25,8 & 4,5 & 3,0 \\
\hline 2. Planejo sair da empresa onde trabalho & 36,4 & 30,3 & 22,7 & 3,0 & 7,6 \\
\hline $\begin{array}{l}\text { 3. Tenho vontade de sair da empresa onde } \\
\text { trabalho }\end{array}$ & 51,5 & 19,7 & 18,2 & 6,1 & 4,5 \\
\hline
\end{tabular}

Fonte: Elaborado pelos autores, com base na pesquisa realizada (2016).

Legenda: N: nunca; R: raramente; AV: às vezes; F: frequentemente; S: sempre.

Com a distribuição dos dados apresentados na pesquisa foi possível identificar informações relevantes para a análise do objeto de estudo da pesquisa. Entre os resultados encontrados, apresenta-se a análise realizada para a interpretação da relação entre a aplicação do treinamento e a intenção de rotatividade de pessoal na percepção dos proprietários e dos funcionários das MPEs pesquisadas.

Este artigo não tem o objetivo de apresentar dados conclusivos acerca do assunto em questão, mas sim observações de uma amostra constituída por 31 MPEs, nas quais 97 respondentes apresentaram suas percepções, convicções, interpretações e fatos gerados em seu ambiente de trabalho, além de informações de características profissionais. A aplicação do processo de treinamento influencia fortemente o ambiente dessas MPEs, e durante a pesquisa foi possível interpretar alguns questionamentos em relação à aplicação do processo de treinamento no ambiente das empresas.

Entre as escalas aplicadas no decorrer do trabalho, pode-se identificar que apresentaram resultados significativos. Ficou evidenciada a forma de aplicação de treinamento por parte das empresas, em que um detalhamento minucioso se tornou necessário para compreender o formato de aplicação do treinamento no ambiente destas empresas. Todas as empresas da amostra confirmaram alguma forma de aplicação de treinamento, principalmente do treinamento no trabalho, porém, percebe-se uma aplicação dos processos de maneira informal em sua maioria.

Esta verificação final só foi possível com a divisão das informações que possibilitaram uma melhor explanação dos dados conforme apresentado no 
início desse capítulo, com a avaliação dos perfis demográficos e profissionais dos indivíduos da amostra, as características apresentadas pelas MPEs, uma interpretação detalhada das práticas de treinamentos aplicadas, e a interpretação dos resultados gerais das escalas ECST, ERTR e EIR.

Entre os resultados encontrados foi possível identificar a aplicação dos quatro tipos de treinamentos investigados na pesquisa e também sua frequência de aplicação. Outro fator que chama a atenção é a aplicação das ações relacionadas ao processo de treinamento: apenas quatro empresas afirmaram não as aplicar, já o restante das empresas participantes afirmaram realizar pelo menos parte do processo.

Com essas informações pode-se compreender que as MPEs da amostra têm se preocupado com esses processos, assim, os resultados demonstram sua proximidade com os processos de treinamento. Contudo, vinte e uma empresas confirmaram não ter um orçamento estipulado para aplicação do treinamento e sim uma prática de realizar os investimentos conforme apresentação de necessidades ou oportunidades. Outra informação levantada relaciona-se às instalações para treinamento, ao pagamento de treinamento externo e à formação de instrutores, sendo que apenas sete empresas afirmaram não desenvolver nenhuma dessas atividades citadas, enquanto as outras empresas afirmaram aplicar parte desses processos.

Assim, com esta análise dos processos de treinamento, fica evidente que as empresas apresentam certa intimidade com a aplicação de treinamento e seus processos. O estudo demonstrou que elas têm contato significativo e esta realidade apresentada leva a considerar que as informações coletadas são de empresas que estão constantemente em contato com treinamento. Esta constatação é algo relevante para o estudo, uma vez que para apresentar se há relação entre treinamento e rotatividade de pessoal é imprescindível esse nível de contato com o processo de treinamento. A Figura 1 apresenta os resultados encontrados no desenvolvimento da pesquisa. 
Figura 1 - Estrutura metodológica de interpretação dos resultados do relacionamento entre treinamento e rotatividade de pessoal

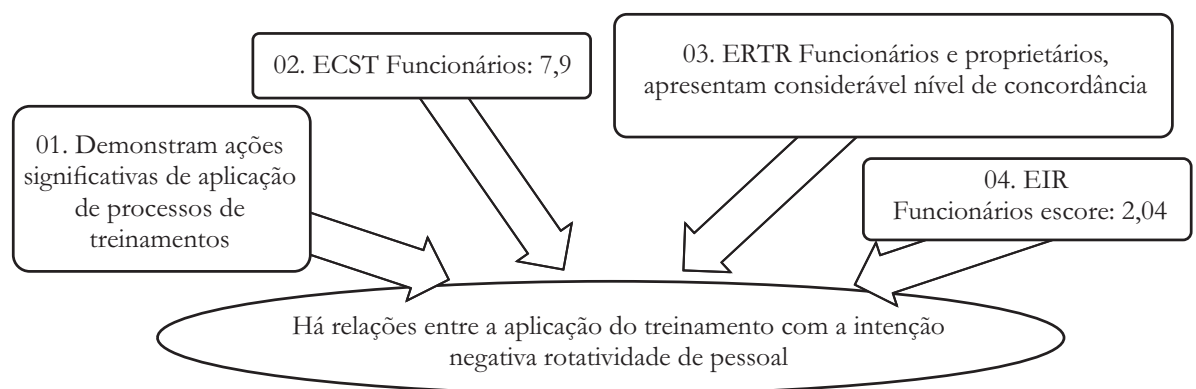

Fonte: Elaborado pelos autores, com base na pesquisa realizada, 2016.

Com as comparações realizadas, fica evidenciado o fato de que o processo de treinamento pode influenciar na rotatividade de pessoal, em que os resultados demonstraram que as MPEs pesquisadas aplicam de forma constante processos ligados a prática de treinamento. Já as escalas demonstram que os participantes consideram que esta prática minimiza os resultados de rotatividade, principalmente com informações coletadas na escala ERTR. Os cruzamentos dessas informações levaram a compreensão de que empresas que utilizam ações de treinamento apresentam índices satisfatórios na percepção de seus proprietários e funcionários quanto aos benefícios para redução da rotatividade de pessoal.

\section{CONCLUSÕES}

Este trabalho abordou temas referentes a treinamento, rotatividade de pessoal e mudanças no ambiente organizacional, no segmento das MPEs, visto que se trata de temas debatidos em diversas pesquisas, nas últimas décadas, dada sua relevância.

Nesse estudo, ressalta-se a utilização de alguns tipos de treinamento (de integração, no trabalho, formal interno ou formal externo), com uma frequência de aplicação variável entre eles, visto que práticas dos processos de treinamentos são aplicadas parcialmente, observando-se, na maioria dos casos, a falta de formalização das atividades de treinamento. Além disso, notou-se que há preferência para discussão em grupo, palestras e orientação da chefia para a aplicação dos métodos e técnicas. 
Quanto às crenças apresentadas pelos indivíduos participantes, surgiram resultados positivos frente ao sistema de treinamento aplicado no ambiente das MPEs pesquisadas, da mesma forma que há um nível significativo de concordância em relação à aplicação do processo de treinamento e sua influência na rotatividade de pessoal, conforme apresentado na escala ERTR.

As principais contribuições desse estudo relacionam-se ao fato de a amostra ser formada por empresas de segmentos diferentes e apresentar características diversas. Este fator contribuiu para uma visão mais completa em relação aos resultados.

As limitações apresentadas nesta pesquisa estão relacionadas à escolha e ao tamanho da amostra (trinta e uma empresas), ao número de indivíduos participantes (97 respondentes), e o fato de a pesquisa ter sido aplicada em apenas um município. A compreensão deste relacionamento ainda necessita de um maior número de pesquisas e debates para acrescentar informações e resultados com outras amostras e instrumentos metodológicos ao tema em questão. Para futuros trabalhos, visando complementar os resultados alcançados, sugere-se empresas da região que não foram analisadas, empresas industriais, além de pesquisas em outras regiões, com empresas relacionadas à amostra do presente trabalho.

Por fim, a pesquisa contribui para compreender o ambiente organizacional e as percepções dos indivíduos que atuam nessas empresas, frente ao relacionamento da aplicação de treinamento com a rotatividade de pessoal e entende que o treinamento é algo fundamental para uma estruturação profissional das MPEs.

\section{REFERÊNCIAS}

ABBAD, D. S. et al. Medidas de avaliação em treinamento, desenvolvimento e educação: ferramentas para gestão de pessoas. Porto Alegre: Artmed 2009. AGAPITO, P. R. et al. Bem-estar no trabalho e percepção de sucesso na carreira como antecedentes de intenção de rotatividade. RAM. Revista de Administração Mackenzie, São Paulo, v. 16, p. 71-93, 2015.

ARMSTRONG, M. A handbook of human resource management practice. Londres: Kogan Page Publishers, 2006. 
BORGES-ANDRADE, J. E.; DE OLIVEIRA-CASTRO, G. A. Treinamento e desenvolvimento: reflexões sobre suas pesquisas científicas. Revista de Administração, São Paulo, v. 31, p. 112-125, 1996.

BROWN, B. L. Training practices for small businesses. Practice Application Brief, p. 4, 1999.

CARDOSO, M. F.;-FREITAS CARDOSO, J. ;-SANTOS, S. R. O impacto da rotatividade e do absenteísmo de pessoal sobre o custo do produto: um estudo em uma indústria gaúcha. Revista de Gestão, Finanças e Contabilidade, Senhor do Bomfim, v. 3, n. 1, p. 107, 2013.

CARVAlHO, S. D.; MOURÃO, L. Análise de necessidade de treinamento em call centers. Revista Eletrônica de Administração, Porto Alegre, v. 20, p. 740-772, 2014.

CRONBACH, Lee J.; MEEHL, Paul E. Construct validity in psychological tests. Psychological bulletin, v. 52, n. 4, p. 281, 1955.

DAWE, S.; NGUYEN, N. Education and training that meets the needs of small Business: a systematic review of research. Adelaide, Australia: NCVER, 2007.

DEMO, G. et al. Políticas de gestão de pessoas no novo milênio: cenário dos estudos publicados nos periódicos da área de Administração entre 2000 e 2010. RAM. Revista de Administração Mackenzie, São Paulo, v. 12, p. 15-42, 2011. DESSLER, G. Administração de recursos humanos. São Paulo: Prentice Hall, 2003.

DESSLER, G. Administração de recursos humanos. 3. ed. São Paulo: Pearson, 2014.

FERREIRA, L. C. D. M.; ALMEIDA, C. B. D. A. Rotatividade de funcionários e desempenho organizacional: um estudo no comércio brasileiro. Brazilian Business Review, Vitória, v. 12, n. 4, p. 28, 2015.

FERREIRA, M. L. C. B.; SIQUEIRA, M. M. M. Antecedentes de intenção de rotatividade: estudo de um modelo psicossocial. Revista Organizações em Contexto, São Paulo, v. 1, n. 2, p. 47-67, 2005. 
FERREIRA, V. C.; FORTUNA, A. A.; TACHIZAWA, T. Gestão com pessoas: uma abordagem aplicada às estratégias de negócios. São Paulo: FGV, 2006.

FREIRE, D. A. Treinamento e desenvolvimento em recursos humanos: encenado e efetivando resultados. Curitiba: InterSaberes, 2014.

FREITAS, A. D. G. et al. A. Intenção de rotatividade: um enfoque a partir das políticas de recursos humanos e da percepção de oportunidades de aprendizagem nas organizações. In: ENCONTRO DA ANPAD, 39., 2015, Belo Horizonte. Anais [...]. Belo Horizonte: ANPAD, 2015. p. 1-17

FREITAS, I. A. D.; BORGES-ANDRADE, J. E. Efeitos de treinamento nos desempenhos individual e organizacional. Revista de Administração de Empresas, São Paulo, v. 44, p. 44-56, 2004.

GONÇALVES, A.; MOURÃO, L. A expectativa em relação ao treinamento influencia o impacto das ações de capacitação? Revista de Administração Pública, Rio de Janeiro, v. 45, p. 483-513, 2011.

GONZAGA, G.; CAYRES PINTO, R. Rotatividade do trabalho e incentivos da legislação trabalhista. Rio de Janeiro: PUC-Rio, 2014. (Texto para Discussão, n. 625).

GONZALEZ, M. J. T\&D e as interfaces com a gestão de pessoas. In: BOOG, G.; BOOG, M. (ed.). Manual de treinamento e desenvolvimento: gestão e estratégias. São Paulo: Pearson Prentice Hall, 2006. p. 256-262

IPEA. Brasil em desenvolvimento 2014: Estado, planejamento e políticas públicas. Brasília: IPEA, 2014.

LACERDA, É. R. M.; ABBAD, G. Impacto do treinamento no trabalho: investigando variáveis motivacionais e organizacionais como suas preditoras. Revista de Administração Contemporânea, Maringá, v. 7, p. 77-96, 2003.

LACOMBE, F. J. M. Recursos humanos: princípios e tendências. São Paulo: Saraiva, 2005.

LOPES, J. M.; MOURÃO, L. Crenças acerca do sistema de treinamento: a predição de variáveis pessoais e funcionais. Estudos de Psicologia, Campinas, v. 27, p. 197-206, 2010.

MALVEZZI, S. A gestão de pessoas no contexto da estrutura de redes: desafios para a sociedade, empresas e indivíduos. Perspectivas em Gestão \& Conhecimento, João Pessoa, v. 3, n. 3, p. 6-17, 2013. 
MARCONI, M. D. A.; LAKATOS, E. M. Fundamentos de metodologia científica. 5. ed. São Paulo: Atlas, 2003.

NONAKA, I.; TAKEUCHI, H. Teoria da criação do conhecimento organizacional. In: NONAKA, I.; TAKEUCHI, H. Gestão do conhecimento. Porto Alegre: Bookman, 2008. p. 54-90.

PEQUENO, Á. Administração de recursos humanos: São Paulo: Pearson Education do Brasil, 2012.

ROBBINS, S. P. Fundamentos do comportamento organizacional. São Paulo: Pearson Prentice Hall, 2004.

ROBBINS, S. P. Comportamento organizacional. 11. ed. São Paulo: Pearson Prentice Hall, 2005.

ROBBINS, S. P.; JUDGE, T.; SOBRAL, F. Comportamento organizacional: teoria e prática no contexto brasileiro. São Paulo: Pearson Prentice Hall, 2010.

SACCOL, A. Z. et al. V. M-learning (mobile learning) in practice: a training experience with IT professionals. JISTEM - Revista de Gestão da Tecnologia e Sistemas de Informação, São Paulo, v. 7, n. 2, p. 261-280, 2010.

SILVA, M. E. D. Relações entre impacto do treinamento no trabalho e estratégia empresarial: o caso da Eletronorte. Revista de Administração Contemporânea, Maringá, v. 10, p. 91-110, 2006.

SILVA, N. S. O.; MOURÃO, L. A influência dos estilos de liderança sobre os resultados de treinamento. Estudos e Pesquisas em Psicologia, Rio de Janeiro, v. 15 , n. $1,2015$.

SILVA, R. D. S.; CAPPELLOZZA, A.; COSTA, L. V. O impacto do Suporte Organizacional e do Comprometimento Afetivo sobre a Rotatividade. Revista de Administração IMED, Passo Fundo, v. 4, n. 3, p. 314-329, 2014.

SIQUEIRA, Mirlene Maria M. Novas medidas do comportamento organizacional: ferramentas de diagnóstico e de gestão. Artmed Editora, 2014.

SOBRAL, F.; PECI, A. Administração: teoria e prática no contexto brasileiro. São Paulo: Pearson Prentice Hall, 2008. 
WEBSTER, B.; WALKER, E.; BROWN, A. Australian small business participation in training activities. Education + Training, Bingley, v. 47, n. 8/9, p. 552-561, 2005.

YIN, R. Estudo de caso: planejamento e métodos. Porto Alegre: Bookman, 2005.

ZARDIN PATIAS, T. et al. Custos da rotatividade de pessoal: evidências no setor de supermercados. Revista de Administração, Contabilidade e Economia, Joaçaba, v. 14, n. 1, p. 28, 2014-12-10 2015.

ZERBINI, T.; ABBAD, G. Impacto de treinamento no trabalho via internet. RAE eletrônica, São Paulo, v. 4, n. 2, art. 16, 2005.

ZERBINI, T.; ABBAD, G. Construção e validação de uma escala de transferência de treinamento. Psicologia: Ciência e Profissão, Brasília, v. 30, p. 684-697, 2010. 